\title{
Economic Feasibility Analysis of PVAC and TAC of Three Typical Application Cases in China
}

\author{
Dan Zhou (D), ${ }^{1}$ Haoran Wang, ${ }^{1}$ Cheng Zhang, ${ }^{1}$ Ke Sun, ${ }^{2}$ Hanyun Wang, ${ }^{3}$ Lihua Zhou, ${ }^{3}$ \\ Jian $\mathrm{Wu}^{4}{ }^{4}$ and Yaojie $\mathrm{Hu}^{4}$ \\ ${ }^{1}$ College of Information Engineering, Zhejiang University of Technology, Hangzhou 310023, China \\ ${ }^{2}$ State Grid Zhejiang Electric Power Company, Ltd., Hangzhou 310008, China \\ ${ }^{3}$ State Grid Huzhou Power Supply Company, Huzhou 313000, China \\ ${ }^{4}$ Huzhou Xinlun Comprehensive Energy Service Co, Ltd., Huzhou 313000, China
}

Correspondence should be addressed to Dan Zhou; zhoudan@zjut.edu.cn

Received 6 May 2021; Revised 20 June 2021; Accepted 23 July 2021; Published 5 August 2021

Academic Editor: Xiaoqing Bai

Copyright (C) 2021 Dan Zhou et al. This is an open access article distributed under the Creative Commons Attribution License, which permits unrestricted use, distribution, and reproduction in any medium, provided the original work is properly cited.

Solar photovoltaic driven air conditioning (PVAC) system with electricity storage is proposed as a good solution to help shifting peak load and consuming solar energy. In this paper, a grid-connected PVAC system using the TRNSYS simulation model consisting of PV panels, traditional air conditioners (TAC), power conditioning units, inverters, and grid connection equipment is proposed to investigate the economic feasibility compared with the traditional air conditioner. In the PVAC system, the electricity, firstly generated by PV panels and then stored in battery, is consumed by a DC inverter air conditioner to maintain the temperature of the room and the surplus electricity is sold to the grid. A life cycle cost comparison between PVAC system, traditional air conditioning system, and decomposed PV and air conditioning systems of three typical application cases is conducted, in which the operation conditions are based on the present circumstances of China. The results show that, in comparison with conventional air conditioners, better economic benefits can be achieved when the peak load of the air conditioning system is over a certain value. Sensitivity analysis is conducted to evaluate the effects caused by variation of economic assumptions. At last, a new operation model is proposed to achieve more benefits for the system.

\section{Introduction}

Nowadays, peak load reduction, carbon emission reduction, and renewable energy curtailment reduction are three main problems threatening the progress and development of the electricity department in China [1].

Peak load reduction can be achieved by strategic conservation, load shifting, and flexible load shape [2]. Thus, an increase in the capacity factors of devices of the grid can be achieved. However, in China, base load is produced by coal power plants, whereas peak load is provided by nuclear, hydro-, or renewable power [3]. Thus, electricity generation during the peak period is more expensive than that during the off-peak period. Besides, installed power capacity should be larger than peak load to ensure the security of the power supply [4]. Based on these two reasons, there is great significance for reducing peak electricity load not only for reducing capital cost but also for higher capacity factor.

Solar energy is known to be clean energy and without carbon emission in power generation. It has been widely used in the combination with buildings for cooling in the previous years. Ai-Alili et al. [5] reported an experimental investigation of a hybrid solar air conditioner system. The experimental results show that the hybrid AC is more effective than the standalone $\mathrm{AC}$ in maintaining indoor conditions within the comfort zone. Zapalowicz and Opiela [6] presented an air conditioning system that consists of a conventional air conditioner, ground heat exchanger (GHE), and PV installation, mounted on the vertical, south-exposed wall of the building. The results showed that the efficiency of PV is improved. Goldsworthy [7] reported a building thermal design method for solar photovoltaic air 
conditioning; the results showed that, in tropical climates, there are certain building thermal designs that lead to indoor temperatures $<25^{\circ} \mathrm{C}$ at all times with a modest size PVbattery system. Huang et al. [8] studied a solar air conditioning system directly driven by standalone solar PV. They found that if solar photovoltaic power generation is not large enough, there will be power loss in the air conditioning system, and an appropriate system design is needed to match the power consumption of the air conditioning system with the appropriate photovoltaic size. Aguilar et al. $[9,10]$ analyzed the viability of the use of photovoltaic systems to supply energy to air conditioning equipment without batteries or regulators. Fischer et al. [11] studied the impacts of PV and variable prices on optimal system sizing for heat pump and thermal storage. Liu et al. [12] studied the composition and principle of an air conditioner driven by a grid-connected photovoltaic (PV) system and analyzed the working principle of quasigrid-connected energy-saving technology. Wei et al. [13] designed a direct current (DC) air conditioning system powered by a solar photovoltaic module (PV) to solve the problem of temperature increase inside the vehicle when it stops in the summer.

However, with the ever-increasing penetration rate of renewable electricity power generation, problems of intermittence and fluctuation threaten the security of the grid significantly [14]. Though the introduction of the smart grid can solve these problems partly, the origin cannot be solved [15]. To offset the effects of intermittence and fluctuation caused by the increase in renewable electricity, the best technical route is consuming as much renewable electricity itself as it can [16].

According to [17], 19.5\% of total energy is consumed as building energy consumption in 2013. It is known that building energy consumption mainly comes from cooling and heating. Thus, meeting the requirement of building load by consuming as much renewable electricity as possible is a good solution consuming renewable electricity and decreasing peak load, thus increasing the capacity factor of the grid. PV air conditioning is thus proposed as one of the solutions to meet the balance between electricity generation and consumption.

Because the cooling/heating load and the energy consumption of air conditioning system in buildings like supermarkets and office buildings are in phase with solar radiation intensity, solar PVAC thus becomes an ideal variable load generating device, which better suits the balance of electricity supply and demand especially when combined with electricity storage [8].

In the early stage, the cost of PV panels is very high, so Bolocan and Boian [18] thought that the high initial cost of a solar air conditioning system is the major obstacle for largescale implementation. In that circumstance, some researchers have made an economic comparison between PV air conditioning system and other solar-driven chillers. Lazzarin [19] made an investment cost comparison and efficiency comparison between solar thermal driven sorption and PV-driven compression chillers. They anticipate that the $\mathrm{PV}$-driven compression chillers have a better application prospect due to the lowering of the investment cost of $\mathrm{PV}$ panels and to the progress of their efficiency. Based on previous studies, Infante Ferreira and Kim [20] made a techno-economic review to investigate the most promising and attractive alternatives when solar energy is used to meet the cooling demands. Finally, they concluded that the PVdriven vapor compression cycles are the most attractive technical route.

In recent years, with great cost reduction of PV panels, PV air conditioning becomes a practical technical route. Allouhi et al. [21] investigated the potential of solar air conditioning in Morocco in hot climates assessing its economic and environmental impacts. Their major finding is that though solar air conditioning is an attractive alternative to mitigate greenhouse gas emissions and increase energy savings, however, the high capital cost is the major obstacle for their implementation. To solve this problem, Tarigan et al. [22] made a cost analysis of the proposed grid-connected system, which includes total capital cost, payback period, and standardized costs. The simulation result showed that the most cost-efficient way to connect PV panels and air conditioning for a classroom of a university is through a grid-connected system. To reduce the capital cost of battery and any inverter regulators, Aguilar et al. [23] carried out an experimental study and analyzed the possibility of using PV panels to power the compressor of DC inverter air conditioning without batteries or any inverter regulators. The experimental result showed that during summer days the solar contribution of PV panels is about $65 \%$ and during heating days the solar contribution of PV panels is about $50 \%$. Li et al. [24] studied the performance of a solar PVAC system in the hot summer and cold winter zone. Based on the experimental results, they concluded that the PVAC can be a good solution to reduce the peak load of electrical grid in the areas where weather condition is similar to Shanghai.

However, to the best of the authors' knowledge and according to the comprehensive literature review, there is no research on the influence of the price differences between peak electricity and valley electricity, centralized PV power generation, and distributed power generation, and individual user and business user were neglected in the previous studies. In fact, economic factors especially price differences are decisive factors for development of PV industry. Moreover, some special application cases of PVAC were studied, but the more general application cases such as using in supermarket and office building were never discussed. Thus, this paper studies the economic feasibility of PVAC system considering three application cases. By making economic comparison between PVAC, TAC, and decomposed PV and AC system of three typical application cases, the economic feasibility of PVAC is verified.

\section{System Description and Methods}

2.1. System Description and Process. The block diagram of the PVAC system is shown in Figure 1. The system consists of PV panels, a commercial variable frequency split type air conditioner, a DC/DC converter, a PEM controller, a DC/ $\mathrm{AC}$ inverter, and battery packs. In this system, the air 


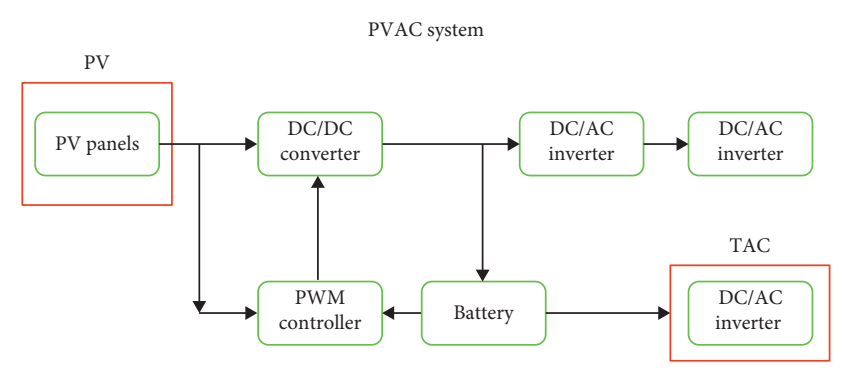

Figure 1: Block diagram of the PVAC system.

conditioner can be connected to the grid in case of lacking electricity powered by the PV arrays and the battery packs. Furthermore, the redundant PV electricity can be sent to the grid to achieve better economic benefits. Due to the issue of intermittence and unsteady electricity generated by PV arrays, a DC/DC converter and a PWM controller are applied to stabilize the output voltage. Then, the direct current is converted into alternating current by a DC/AC inverter to meet the air conditioning load or sent to the grid. In order to increase the reliability of powering PV panels, battery packs are usually used as an electricity storage device. When lacking electricity, the battery packs will work.

The existing electricity pricing schemes include time of use, critical peak price, real-time price, and so on. Time of use (TOU) refers to the different electricity prices set by the power sector for different types of users according to time periods, dates, and seasons. Critical peak price (CPP) is based on the time of use (TOU) price, which adds a new price for an extreme peak period, namely, critical peak price. Real-time price is a kind of dynamic electricity price, electricity price, and electricity cost linkage, reflecting the real-time supply and demand situation of the electricity market. Users can respond to real-time changes in electricity prices. This paper adopts the time of use price, which will be introduced in detail in Section 3.1.

2.2. Operation Case of Air Conditioning System. LCC (life cycle cost) refers to all costs related to the product during its effective use, including product design cost, manufacturing cost, procurement cost, use cost, maintenance cost, and waste disposal cost.

The LCC analysis studies the total cost over the lifespan of the PVAC system, which includes the capital cost of PV arrays and air conditioning, greenhouse gas emission, electricity consumption, operation and maintenance cost, and residual value. The economic analysis is carried out by comparing the key economic indicator of LCC using PVAC and TAC under three typical cases. Case 1 is a typical application in a supermarket with a working period from 08:00 to 21:00. In case 2, the air conditioning system runs in an office building, where the operation period is from 07:00 to 18:00. For the 3rd case, the system is run in residential in rural areas; thus, the working time for the air conditioning system is assumed to be 19:00 to next 06:00.

\subsection{Life Cycle Cost Calculation Methods}

2.3.1. Life Cycle Cost. Based on the LCC methodology evaluating the potential economic impact on an air conditioning system throughout its lifespan, the economic efficiency of the system is evaluated. The model is developed by grouping the cost into four categories and comprises capital cost $\left(C_{C}\right)$, operation and maintenance cost $\left(C_{O \& M}\right)$, residual value $\left(C_{\mathrm{RV}}\right)$, and greenhouse gas emissions cost $\left(C_{\mathrm{GGE}}\right)$. The relationship of these factors is combined as

$$
\mathrm{LCC}=C_{C}+C_{\mathrm{O} \& M}-C_{\mathrm{RV}}+C_{\mathrm{GGE}} .
$$

Generally, the LCC is converted into a present value, which is widely applied when comparing cash flows at different times. Expressed in the form of a present value, LCC is calculated as

$$
\mathrm{LCC}=C_{C}+\sum_{i=1}^{n} \frac{C_{\mathrm{O} \& M, i}}{(1+r)^{i}}-\frac{C_{\mathrm{RV}}}{(1+r)^{n}}+C_{\mathrm{GGE}},
$$

where $n$ refers to the lifetime calculated by year. In this study, the lifetime of $n$ is 25 ; a constant value of $r=6 \%$ is adopted as the discount rate during the lifespan of the system.

In the PVAC system, capital cost mainly refers to the sum of the cost of land, building construction, instruments, and equipment. Considering the fact that most PV arrays are installed in roofs of buildings, the cost of land can be neglected when compared with the TAC system. In this study, the capital cost is paid off by investors.

For the PVAC system, the cost of operation and maintenance is mainly formed by the cost of labor and maintenance. The PV arrays need to be cleaned every week and the air conditioning system needs to be inspected every month. Maintenance cost contains the cost of regular maintenance and disaster recovery. According to the experience of the PV system and air conditioning system, the cost of labor and maintenance is estimated to be $2 \%$ of the capital cost every year. Besides, the cost of electricity is another significant part of this cost. The compound present worth of operation and maintenance cost is calculated:

$$
C_{\mathrm{O \& M}}=\sum_{i=1}^{n} \frac{2 \% \times C_{C}+C_{\mathrm{ele}, i}}{(1+r)^{i}}
$$

where $C_{\text {ele, } i}$ refers to the cost of electricity yearly and $r$ is the discount rate.

The value of residual of fixed assets means the expected value at the end of the life of the assets. According to [25], a residual rate of $d=5 \%$ of the total price of fixed assets is commonly adopted. The residual value of the PVAC system lies in the worth of reusable units of PV arrays and air conditioning system. The residual value is calculated by applying

$$
C_{\mathrm{RV}}=\frac{d \times C_{C}}{(1+r)^{n}}
$$

The environmental impact that needs to be considered includes four categories: greenhouse gases emission, eutrophication effect, acidification effect, and winter smog 
effect. Compared to the environmental impact caused by the manufacture of air conditioning system, PV arrays is the major source of pollution.

However, only carbon dioxide is under consideration in China currently. Other pollutions, like nitrogen oxides, sulfur dioxide, and so on, are not considered. Thus, the environmental impact cost mainly comes from equivalent carbon dioxide emission. The environmental impact inventory for multi-Si PV power production is shown in Table 1. The tax is estimated to be $\$ 7.5 /$ ton eq- $\mathrm{CO}_{2}$ [26].

2.4. Economic Indicators. LCC, an important economic indicator in many economic analyses, provides a comprehensive understanding of the economics of the PVAC system. It provides decision makers with a set of references on which project planning decisions can be made [28].

Besides LCC, the discount rate is another key economic parameter to evaluate the economic behavior. A discount rate of $6 \%$ is adopted in this study for economic analysis.

2.5. Sensitivity Analysis. The objective of sensitivity analysis is to understand how uncertainties in input parameters impact important economic indicators. Besides, the sensitivity results will also find out the most important parameters, which have significant impacts on the economic benefit index of the investment project among these uncertain parameters. In this study, the capital costs of equipment including PV system and air conditioning system, price of peak electricity and valley electricity, on-grid price of PV power generating, and operating hours of air conditioning system and PV system are investigated as the main uncertainties. Besides these parameters, the perturbation of discount rate, which shows the present value of future expenses is also investigated.

\section{Economic Life Cycle Inventory (ELCI)}

The ELCI describes the whole process included in the system boundaries, which can be seen in Section 2.1. The LCC is typically divided into three phases: construction, utilization, and decommissioning. Of course, the cost of construction and utilization for the air conditioning system is the major cost-consuming phase. The economic data and technical parameters of equipment are collected in the following section. The case is divided into three cases: case 1 , case 2, and case 3 . The case analysis will be carried out by making a comparison between the PV air conditioning system and the TAC system.

3.1. Economic Data Collection. As power conditioning units, the DC/DC converter, PWM controller, and DC/AC inverter are used in this system. The price of PV arrays, DC/AC inverter, DC/DC converter, battery bank, and PWM controller is assumed to be $\$ 1000 / \mathrm{kWp}, \$ 85 / \mathrm{kW}, \$ 120 / \mathrm{kW}$, $\$ 150 / \mathrm{kWh}$, and $\$ 25 / \mathrm{kW}$. For the cost of electric power distribution, an addition of $\$ 460 / \mathrm{kW}$ is adopted for the increase of power distribution equipment. The cost of an air
TABLE 1: Environmental impact inventory for multi-Si PV power production [27].

\begin{tabular}{lcc}
\hline Item & Value & Unit \\
\hline Carbon dioxide emissions & 132.91 & $\mathrm{~kg} / \mathrm{kWp}$ \\
Carbon monoxide emissions & 1.70 & $\mathrm{~kg} / \mathrm{kWp}$ \\
Nitrogen oxide emissions & 279.61 & $\mathrm{~kg} / \mathrm{kWp}$ \\
Sulfur dioxide emissions & 0.79 & $\mathrm{~kg} / \mathrm{kWp}$ \\
\hline
\end{tabular}

conditioning system is about $\$ 540 / \mathrm{kW}$ for which the cooling capacity is calculated based on the Coefficient of Performance (COP) and environmental conditions. These costs of equipment are listed in Table 2 . The price of electricity for industrial and commercial customers during the period of peak electricity, valley electricity, and the other is $\$ 0.1926 /$ $\mathrm{kWh}, \$ 0.0569 / \mathrm{kWh}$, and $\$ 0.1203 / \mathrm{kWh}$, respectively. The price of electricity for residential customers during the period of peak electricity and valley electricity is $\$ 0.0949$ / $\mathrm{kWh}$ and $\$ 0.0472 / \mathrm{kWh}$, respectively. Dividing different types of electricity is based on the time segments, which are shown in Tables 2-4.

\subsection{Technical Parameters of Equipment Collection and Case Analysis}

3.2.1. Air Conditioning System. Generally, the construction cycle is less than several weeks; therefore, the construction cycle is assumed to be 0 in this study. The efficiency of the combination of DC/DC converter and PWM controller is assumed to be $93 \%$. When the system is connected to the grid, a DC/AC inverter with a rated efficiency of $93 \%$ is necessary to output the excessive PV electricity especially during the spring and the autumn. For the lead-carbon battery packs, the efficiency and lifespan are varied inversely with the DOD (depth of discharge). The efficiency of $93 \%$ and the number of 4200 or nearly 15 years of charge-discharge cycles are adopted at the DOD of $70 \%$ [19]. The detailed technical data can be shown in Table 5. Since the COP of the air conditioning system is determined not only by the performance of equipment but also by the conditions of the ambient, it is hard to calculate the exact efficiency over the lifespan of the system. In this study, a simulation platform is constructed using Transient Systems (TRNSYS) to calculate the energy flow of an air conditioning system in Shanghai, a city in the typical climate of hot summer and cold winter in China.

A room with an area of $23.5 \mathrm{~m}^{2}$ and a volume of $75 \mathrm{~m}^{3}$ is adopted as the tested room. The cooling load is assumed to be $150 \mathrm{~W} / \mathrm{m}^{2}$; thus, the total cooling load is $3.5 \mathrm{~kW}$. The detailed structural parameters of the tested room are listed in Table 6. According to the total cooling load, a frequency conversion air conditioner with a rated power of $0.62 \mathrm{~kW}$ is suited for the cooling needs. The main parameters of the air conditioner are shown in Table 7.

3.2.2. Lead-Carbon Battery Pack. Choosing the battery pack is based on the voltage of the system and the required powering days. The voltage is $48 \mathrm{~V}$, and the capacity can be estimated by 
TABLE 2: Summary of cost of different equipment [29].

\begin{tabular}{lcc}
\hline Item & Data & Units \\
\hline Air conditioning & 540 & $\$ / \mathrm{kW}$ \\
Lead-carbon battery packs & 150 & $\$ / \mathrm{kWh}$ \\
DC/AC inverter & 85 & $\$ / \mathrm{kVA}$ \\
DC/DC converter & 120 & $\$ / \mathrm{kVA}$ \\
On-grid price of centralized PV electricity & 0.151 & $\% / \mathrm{kWh}$ \\
On-grid price of PV electricity for business user & 0.103 & $\$ / \mathrm{kWh}$ \\
On-grid price of PV electricity for personal user & 0.126 & $\$ / \mathrm{kWh}$ \\
Power distribution equipment & 460 & $\$ / \mathrm{kW}$ \\
PV panels & 1000 & $\$ / \mathrm{kWp}$ \\
PWM controller & 25 & $\$ / \mathrm{kW}$ \\
\hline
\end{tabular}

TABLE 3: Electricity price for industrial and commercial customers [30].

\begin{tabular}{lcc}
\hline Item & Time & Price $(\$ / \mathrm{kWh})$ \\
\hline & $08: 00-11: 00$ & 0.1953 \\
Peak electricity & $13: 00-15: 00$ & 0.1953 \\
& $18: 00-21: 00$ & 0.1953 \\
Valley electricity & $22: 00-06: 00$ & 0.0519 \\
Others & - & 0.123 \\
\hline
\end{tabular}

TABLE 4: Different stages of electricity for residential customers [31].

\begin{tabular}{lcc}
\hline Item & Time & Price $(\$ / \mathrm{kWh})$ \\
\hline Peak electricity & $06: 00-22: 00$ & 0.0949 \\
Valley electricity & $22: 00-06: 00$ & 0.0472 \\
\hline
\end{tabular}

TABLe 5: Summary of detailed technical data of equipment.

\begin{tabular}{lcc}
\hline \multicolumn{2}{c}{ Item } & Data \\
\hline Battery voltage & & $48 \mathrm{~V}$ \\
DC/DC converter capacity & & $2 \mathrm{kVA}$ \\
DC/AC inverter capacity & & $2 \mathrm{kVA}$ \\
& Battery bank & $93 \%$ \\
Rated efficiency & DC/AC inverter & $90 \%$ \\
& DC/DC converter & $90 \%$ \\
& PWM controller & $95 \%$ \\
\hline
\end{tabular}

TABLE 6: Structural parameters of the tested room.

\begin{tabular}{lcccc}
\hline Item & East & South & West & North \\
\hline Area of the wall $\left(\mathrm{m}^{2}\right)$ & 16.5 & 14.9 & 16.4 & 14.9 \\
Window to wall ratio (\%) & 18 & 28 & 0 & 3 \\
\hline
\end{tabular}

TABle 7: Parameters of the frequency conversion air conditioner.

\begin{tabular}{lc}
\hline Item & Data $(\mathrm{kW})$ \\
\hline Rated $(\min / \max )$ cooling capacity & $2.8(0.8 / 3.6)$ \\
Rated $(\min / \max )$ heating capacity & $3.6(0.8 / 5.2)$ \\
Rated $(\min / \max )$ cooling input power & $0.62(0.17 / 1.10)$ \\
Rated $(\min / \max )$ heating input power & $0.85(0.17 / 1.50)$ \\
\hline
\end{tabular}

$$
C_{\text {battery }}=\frac{E_{\text {daily }}}{V} \times \frac{T}{\eta_{\text {inverter }} \cdot \text { DOD }},
$$

where $E_{\text {daily }}$ refers to the daily electricity consumption of the system, Wh. To meet the requirements on most days, the larger rated power between cooling and heating of $0.85 \mathrm{~kW}$ is adopted. To calculate $E_{\text {daily }}$ precisely, a simulation has been carried out to determine the required electricity and the results are shown in Figure 2. $V$ is the system voltage, $48 \mathrm{~V} . T$ is the rainy days, and 1 day is assumed in this study. $\eta_{\text {invertor }}$ is the rated efficiency of DC/AC inverter, it is assumed to be 93\% in this study. The rated DOD of the battery pack is assumed to be $70 \%$. When the capacity is calculated, the real capacity is chosen based on the nearest value from the product series. The results are shown in Table 8 .

3.2.3. PV Panels. To make the balance between supplying sufficient power electricity and minimizing the capital investment, the capacity of panels is calculated by applying [32]

$$
N_{\mathrm{PV}}=\frac{E_{\text {daily }} \cdot f_{\theta}}{m \cdot I_{m} \cdot \eta_{\text {battery }} \cdot f_{e} \cdot S_{P}},
$$

where $f_{\theta}$ refers to the inclination correction factor and is assumed to be 0.99 [32]. $m$ is the average daily sunshine hours under standard testing conditions; it is 4.134 in Shanghai [33]. $I_{m}$ is the current of maximum power point under standard testing conditions, $6.86 \mathrm{~A}$. $\eta_{\text {Battery }}$ is the rated efficiency of the battery, $93 \%$. $f_{e}$ refers to the loss compensation coefficient of PV panels; it is assumed to be 0.9 . And $S_{P}$ is dust blocking factor, 0.96. The peak power of a panel under standard conditions is $120 \mathrm{~W}_{p}$; thus, the peak power of PV panels can be accumulated. The result of the three cases is shown in Table 8 .

\subsection{Systems' Simulation to Calculate the Electricity Con- sumption and Generation of PV Air Conditioning System.} Based on the information, a simulation is carried out to calculate the accurate energy flow for the system. Considering the response character, the time step is chosen as 5 minutes. The results are shown in Table 9 and Figure 3. For case 1 , the annual electricity generation is $2175.2 \mathrm{kWh}$, and the surplus electricity is $1200.8 \mathrm{kWh}$, which is less than the difference between electricity output and consumption. The reason mainly lies in the power loss coming from equipment like batteries and invertors. However, the remaining electricity can be sold to the grid for shortening the payback period. For all three cases, the annual electricity output will go up in proportion to the PV installed capacity; however, the electricity consumption varies differently. On the one hand, the temperature during different periods causes different electricity consumption. On the other hand, the energy consumption of long-time continuous running of an air conditioning system is less than the energy consumption of intermittent running because of the heat capacity of the air and the room. 


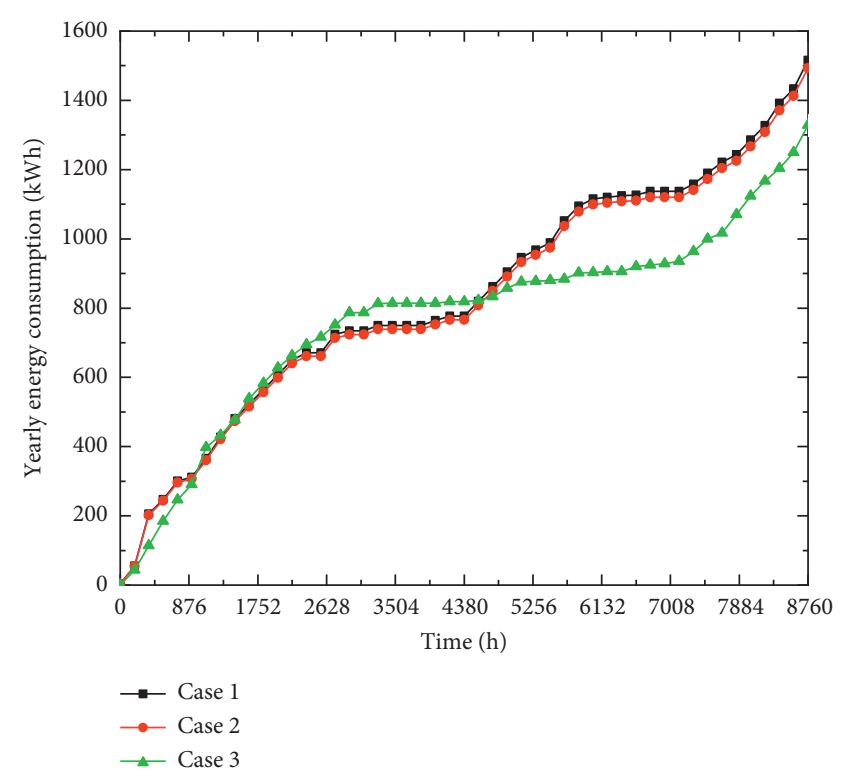

FIgURE 2: Theoretical yearly electricity consumption of three cases.

TABle 8: Annual electricity consumption and technical parameters of three cases.

\begin{tabular}{lccc}
\hline Item & Case 1 & Case 2 & Case 3 \\
\hline $\begin{array}{l}\text { Running period } \\
\begin{array}{l}\text { Cooling temperature } \\
\left({ }^{\circ} \mathrm{C}\right)\end{array}\end{array}$ & $08: 00-21: 00$ & $07: 00-18: 00$ & $19: 00-06: 00$ \\
$\begin{array}{l}\text { Heating temperature } \\
\left({ }^{\circ} \mathrm{C}\right)\end{array}$ & 18 & 26 & 26 \\
$\begin{array}{l}\text { Electricity consumption } \\
\text { (kWh/year) }\end{array}$ & 1515.9 & 1493.6 & 1328.0 \\
$\begin{array}{l}\text { Daily electricity } \\
\text { consumption (Ah) }\end{array}$ & 86.5 & 85.3 & 75.8 \\
$\begin{array}{l}\text { Battery capacity (Ah) } \\
\text { PV installed capacity } \\
(\mathrm{kWp})\end{array}$ & 140 & 140 & 80 \\
\hline
\end{tabular}

TABle 9: The simulation results of energy flow of three cases.

\begin{tabular}{lccc}
\hline Item $(\mathrm{kWh})$ & \multicolumn{3}{c}{ Data } \\
& Case 1 & Case 2 & Case 3 \\
\hline Annual electricity generated & 2175.2 & 2175.2 & 2175.2 \\
Annual electricity remaining & 1200.8 & 1141.9 & 1661.6 \\
\hline
\end{tabular}

\section{Results}

4.1. LCC Analysis of Case 1, Case 2, and Case 3. Once the parameters of costs of equipment, operation and maintenance, and residual are input, the LCC analysis is carried out to render all costs converting to the present value, so that the three typical cases can be compared. According to equations (1) and (2), we can get the following results. The LCC analysis results of three cases of both PVAC and air conditioning are shown in Table 10.

Table 10 shows the LCC of three cases of both PVAC system and air conditioning system. It can be concluded that the PVAC system shows more economic viability compared with the TAC system for case 1 but shows less economic viability compared with the TAC system for case 2 . For case 3 , although it is about individual PV users, the PVAC system also shows more economic viability compared with the TAC system. The LCC of PVAC is $\$ 1986.1$ and the TAC's is $\$ 2620.1$. The LCC of PVAC is $24 \%$ less than that of TAC. Meanwhile, case 1 is $17 \%$ and case 2 is $9.2 \%$. In three cases, PVAC in case 3 shows the most obvious economy. To analyze the reason for the high LCC of the PVAC system and find a solution to reduce the LCC, Figure 3 collects the costs of each stage. Notice that the costs of capital and electricity account for about $82 \%$ of PVAC and over $91 \%$ of air conditioning of all three cases. For PVAC, the cost of the sum of PV panels and battery packs takes account of $79 \%$, $79 \%$, and $76 \%$ of capital cost for three cases, respectively. The LCC is the life cycle cost, which means that the smaller the LCC of one system is, the smaller the money it costs. So, smaller LCC means more economic performance. Therefore, Table 10 indicates that there is a great possibility for capital cost reduction because of the continuous technological progress of PV panels and battery causing substantial cost reduction. Besides, by design optimization of the capacity, better economic benefits can be gained without sacrificing the reliability of the electricity supply.

The cost of electricity is the second significant factor, which accounts for about one-fourth to one-third of the LCC of the PVAC system. Since the surplus electricity is sold to the grid, it seems that there are more economic benefits and lower LCC when the amount of electricity increases, as shown in Figure 4. However, considering the difference of on-grid PV electricity between commercial user, personal user, and centralized power station (the on-grid price of them progressively increases), outputting more electricity means greater economic losses. Thus, reducing electricity output and increasing electricity meet peak valley electricity requirements and reduce the design capacity of PV panels and battery packs.

\subsection{Sensitivity Analysis of PVAC System}

4.2.1. Sensitivity Analysis considering Economic Aspects of Three Cases. To better understand how these economic factors impact the LCC analysis and make comparisons of three cases of PVAC system, sensitivity analysis is conducted. The parameters investigated are the cost of equipment, on-grid price, and the discount rate. The LCC analysis is repeated with all parameters perturbed by $20 \%$. The results are shown in Figure 5.

It can be seen that, among the parameters being investigated, the cost of equipment causes more significant impacts on the LCC of the PVAC system of all three cases. This is not surprising because it accounts for over $52 \%$ of total LCC, which implies that there is plenty of room for reducing the LCC because of the cost reduction caused by technical progress. Besides, these economic parameters that investigated especially on-grid price and discount rate have more impacts on case 3 than the other two cases. This is mainly because case 3 has a higher ratio of electricity price to 


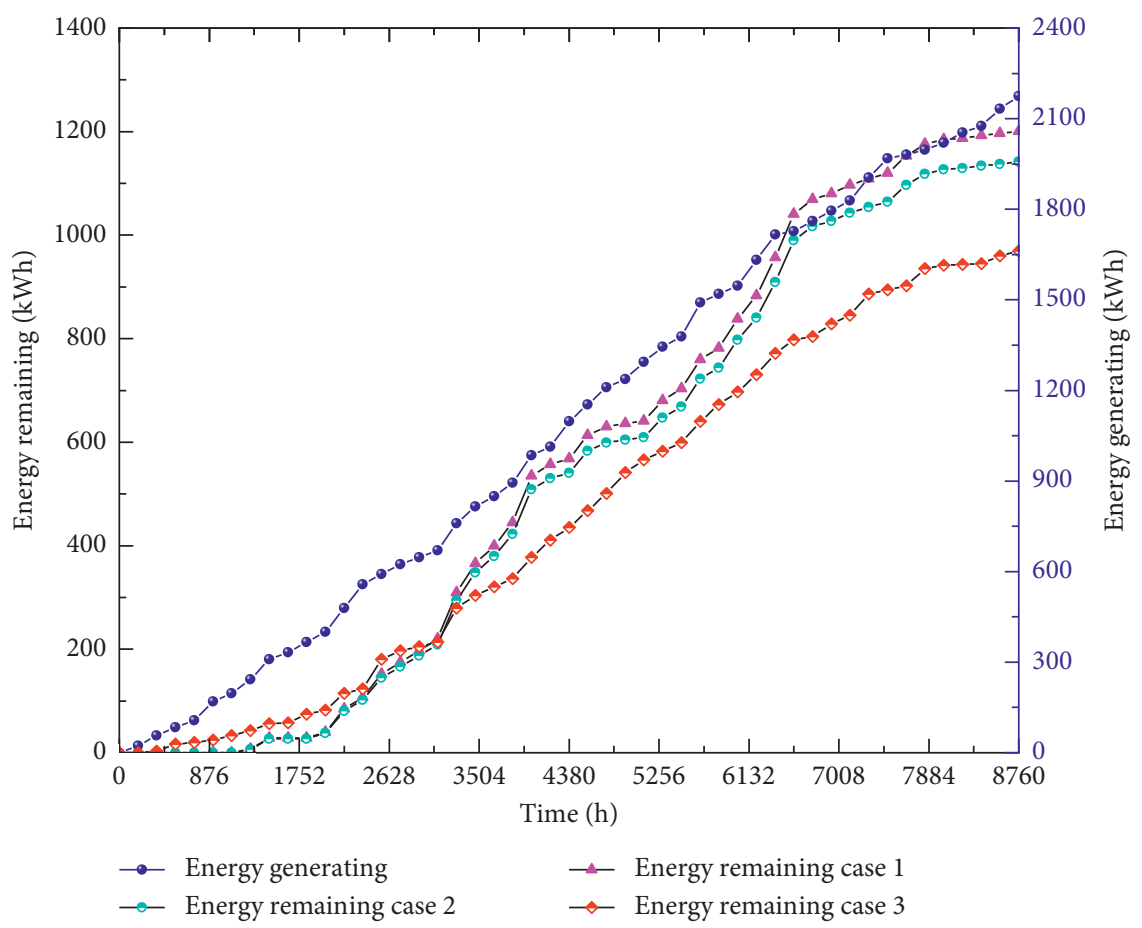

Figure 3: The simulation results of PVAC of three cases.

TABLE 10: Results of LCC analysis of three cases.

\begin{tabular}{lcccccrr}
\hline \multirow{2}{*}{ Item } & \multicolumn{2}{c}{ Case 1 } & \multicolumn{2}{c}{ Case 2 } & \multicolumn{2}{c}{ Case 3 } \\
& PVAC & & TAC & PVAC & TAC & PVAC & TAC \\
\hline LCC $(\$)$ & 3810.1 & & 4571.4 & 3885.3 & 4281.1 & 1986.1 & 2620.1 \\
\hline
\end{tabular}

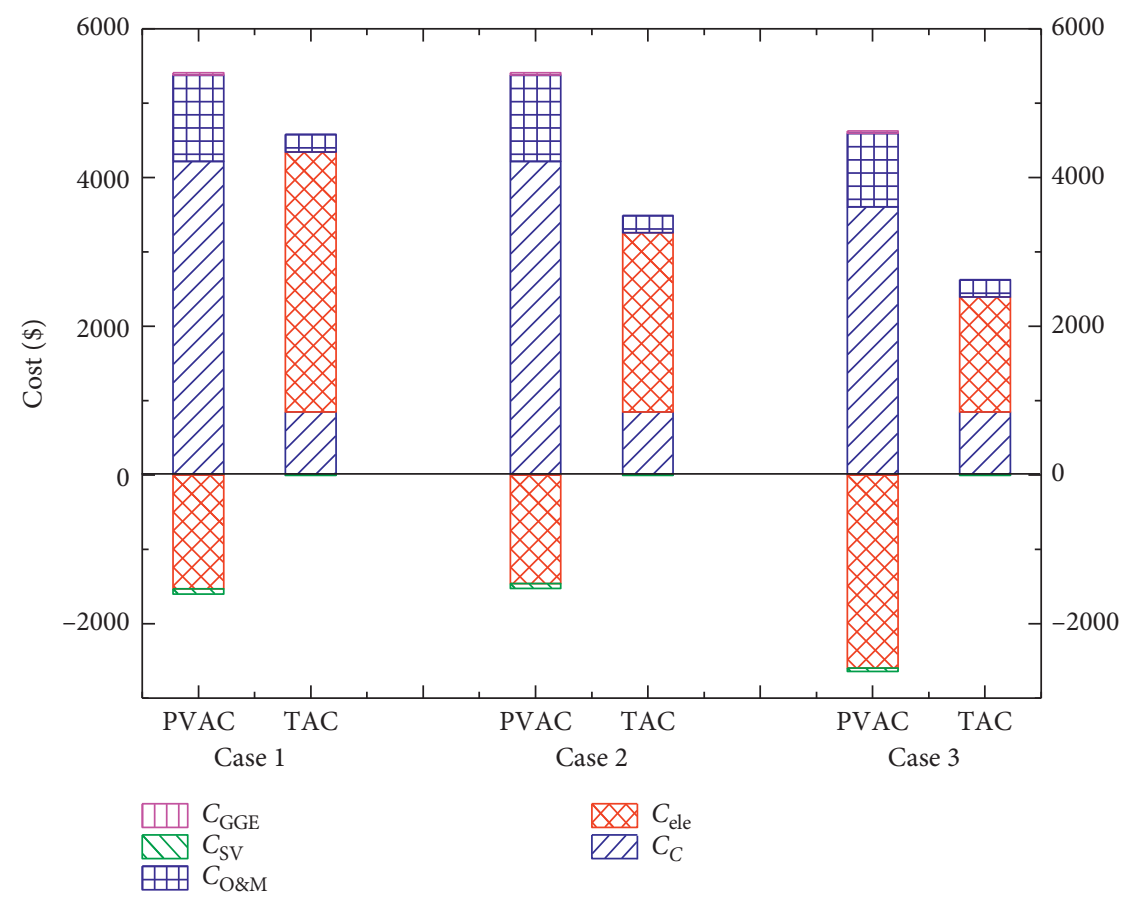

FIGURE 4: LCC analysis of three cases. 


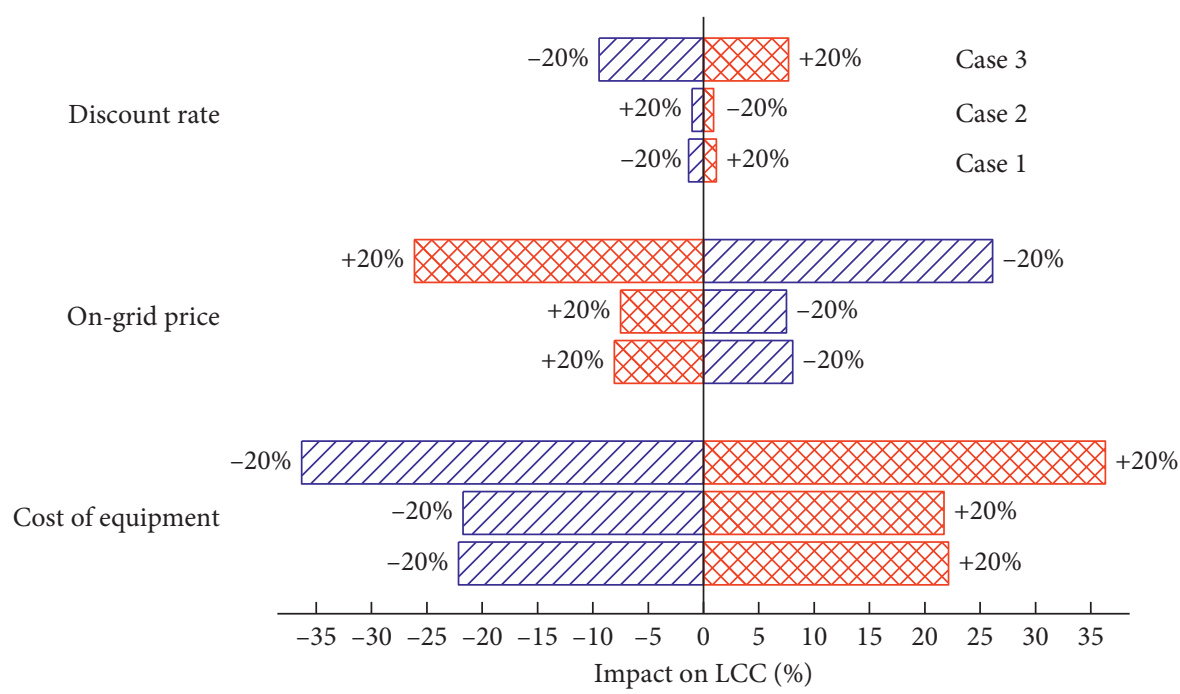

FIGURE 5: Sensitivity analysis considering economic aspects of three cases.

LCC for higher government subsidies for personal users based on incentive policies, though much more electricity is output in case 1. Of course, the LCC of all three cases is more economic than TAC. Therefore, the economic viability comparison between PVAC and TAC will be fully discussed in the next section on three cases.

4.2.2. Sensitivity Analysis considering Technical Aspects of Three Cases. In the former section, the impact of economic factors on LCC has been investigated; however, the economic viability is also influenced significantly by technical aspects. Thus, the sensitivity analysis is conducted to determine how these technical aspects impact the LCC analysis results. The parameters investigated are annual power generation capacity caused by enhancement of PV efficiency, battery capacity, battery efficiency, and efficiency of DC/DC converter. The LCC analysis is repeated with all parameters perturbed by $20 \%$ except the efficiency of the battery. Considering that their rated efficiency is as high as $90 \%$, the perturbation ratio is $+5 \%$ and $-20 \%$. The sensitivity analysis results are shown in Figure 6.

It can be seen from Figure 6 that battery efficiency shows the least impact on LCC while two others have significant impacts; thus, the technical progress of battery cannot promote the commercialization of PVAC. Of course, the LCC decreases with increasing PV efficiency because more electricity is generated. The improvement of PV efficiency and decrease of battery capacity influence the LCC obviously. Particularly, the latter has more significance. A decrease of $20 \%$ battery capacity causes a reduction of nearly $10 \%$ of total LCC because of the high capital cost of the battery. There is still big potential for cost reduction for the PVAC system with the technical progress resulting in cost reduction.

Decreasing the capacity of PV panels and battery capacity makes the PVAC become economical and more competitive. However, decreasing battery capacity can decrease the reliability for system operation and body comfort, which should be avoided in system design.
4.2.3. Economic Viability Comparison between PVAC and TAC in Cases 1 and 2. To better determine the economic boundaries between PVAC and TAC systems, economic viability comparison is carried out in this section. Considering that the peak electricity consumption ratio is low, the impact is discussed in the following section. Since there is little possibility for the on-grid price of PV electricity increasing and the price of peak electricity is expected to be higher in China because of electricity market reform [33], choosing peak electricity price as the variable for LCC is appropriate. The analysis results are shown in Figure 7 of cases 1 and 2.

It can be seen that the LCC of air conditioning increases with the peak electricity price linearly. From left to right, the first value of the $x$-axis of dot refers to the present LCC under the current price of the value of valley electricity price, which is $\$ 0.1230 / \mathrm{kWh}$. For case 1 , when the price of peak electricity increases to the critical point, which is $\$ 0.1360 / \mathrm{kWh}$, both PVAC and air conditioning have the same LCC and economic benefits. So more benefits can be gained when the price of peak electricity is over $\$ 0.1360 / \mathrm{kWh}$. Particularly, the difference of LCC between PVAC and air conditioning is as large as $\$ 761.3$ when the price of peak electricity is $\$ 0.1953 / \mathrm{kWh}$, which is the present price of peak electricity. When the price of peak electricity exceeds the critical value of case 2 that is $\$ 0.1529 / \mathrm{kWh}$, there are economic benefits for PVAC. It can be expected that more benefits can be achieved with the increase of peak electricity in the near future because of electricity market reform boosting the development of renewable electricity power generation. The reform is implementing gradually by National Development and Reform Commission and has achieved preliminary results [34].

4.3. LCC Analysis of Case 1 and Case 2 considering the Curtailed Electricity. Since renewable electricity curtailment hardly happens to individual PV users, the discussion will not include case 3 . To investigate the economic feasibility 


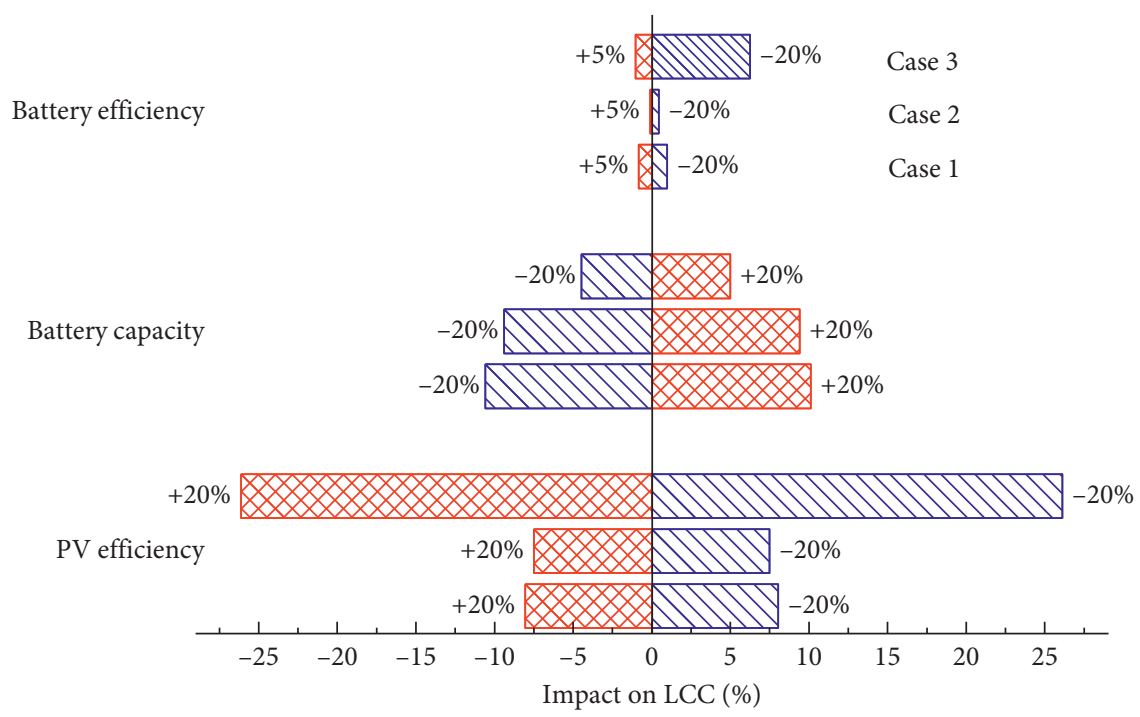

FIGURE 6: Sensitivity analysis considering technical aspects of three cases.

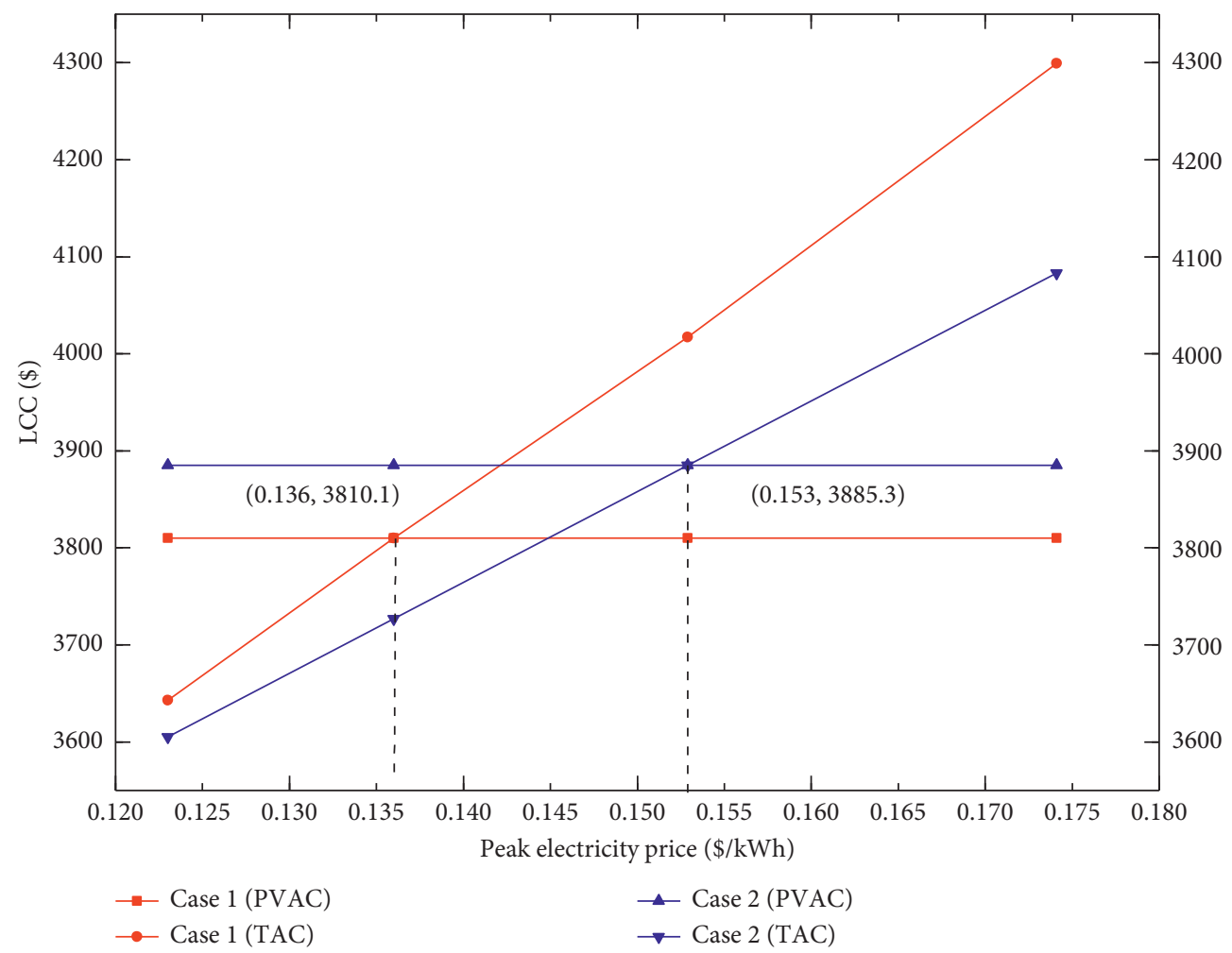

FIgURE 7: The impact of peak electricity price on LCC of cases 1 and 2.

when compared with the decomposed LCC of centralized PV power generation and TAC, an LCC comparison is conducted in this section. Because the PVAC system consumes a great large amount of electricity itself, no electricity is curtailed. However, when carrying out the decomposed LCC, the fact of an average PV electricity curtailment rate of $12.6 \%$ should be considered correspondingly based on the statistical data in China [35]. The detailed flowchart of three ways to use PV electricity is shown in Figure 8.
Because of the obvious disadvantage of PVAC of cases 2 and 3 , the decomposed LCC will be carried out only for case 1. The results are shown in Table 11.

It can be concluded from Table 11 that the LCC from high to low is air conditioning, decomposed PV and air conditioning, and PVAC. Although higher income from selling electricity is achieved, more electric charge is paid for the high cost of peak electricity especially during summer and winter. To investigate the difference between PVAC and 


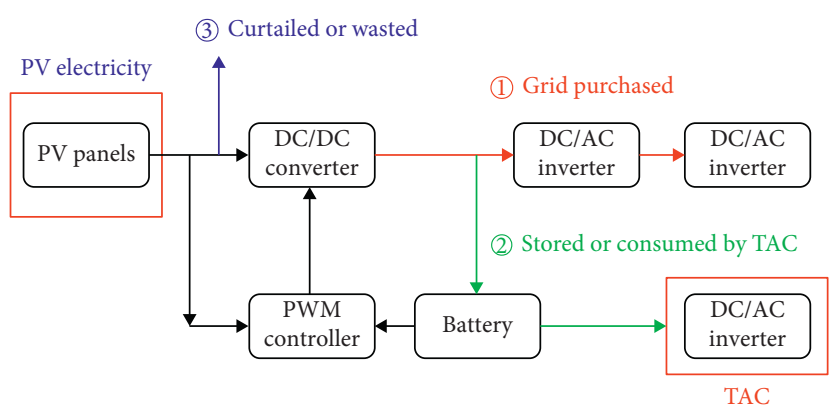

Figure 8: Flowchart of three ways to use PV electricity.

TABLE 11: The results of the LCC when considering a curtailment rate of $12.6 \%$.

\begin{tabular}{lll}
\hline Item $(\$)$ & Case 1 & Case 2 \\
\hline LCC of PVAC & 3810.1 & 3885.3 \\
LCC of TAC & 4571.4 & 4281.1 \\
LCC of decomposed PV and air conditioning & 4282.2 & 3991.9 \\
\hline
\end{tabular}

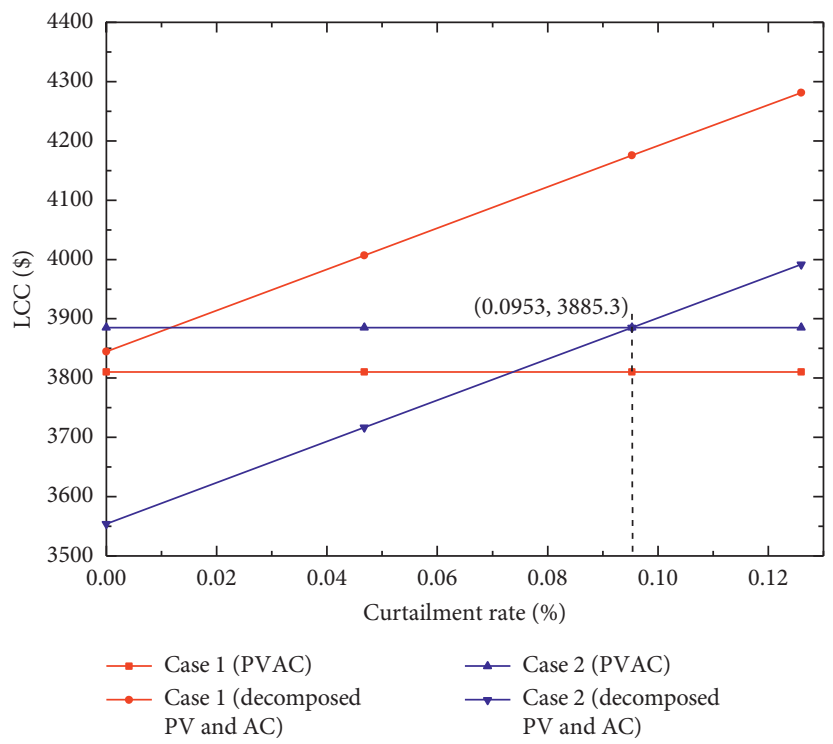

FIGURE 9: LCC comparison between decomposed PV and air conditioning and TAC considering the curtailment rate of case 1.

decomposed PV and air conditioning when the curtailment rate is changing, an analysis is carried out and the result is shown in Figure 9.

Figure 9 leads to the conclusion that, to compete with decomposed PV and air conditioning, the curtailment rate should be over $9.53 \%$ for case 2 , which occurs in many areas of China; thus, the PVAC can be economically feasible. However, for case 1, PVAC is more competitive even if the price of selling electricity is cheaper. Compared with decomposed PVAC, an increase in the cost of power distribution equipment partly offsets the economic benefits coming from higher electricity selling prices for decomposed PV and air conditioning systems. More importantly, a large cost increase of consuming peak electricity brings more negative effects than positive effects of higher electricity selling price for cases consuming much peak electricity like case 1 . However, when peak electricity consumption is reduced, there is a possibility that decomposed PV and air conditioning can achieve more benefits like case 2 .

Although this could lead to the conclusion that PCAV can be economic when faced with cases consuming much peak electricity, it can also be seen that the decomposed PV and air conditioning is economic when the curtailment rate is low enough. To achieve more benefits, a new operation model is proposed in this study combining the advantage of both PVAC of avoiding peak electricity consumption and no curtailment rate and decomposed PV and air conditioning of higher electricity selling price. In the new operation model, the system operates the "PVAC model" during the electricity consuming period (from July to August and from 
TABLE 12: LCC of PVAC operating on the mode of shifting peak electricity load for the grid.

\begin{tabular}{lcc}
\hline Item $(\$)$ & Case 1 & Case 2 \\
\hline Cost of surplus electricity & -607.8 & -455.8 \\
Cost of selling electricity & -666.0 & 666.0 \\
Cost of consuming electricity & 59.62 & 134.3 \\
LCC & 3794.3 & 4165.8 \\
\hline
\end{tabular}

December to next April) and operates the "decomposed PV and air conditioning model" during other days, which will be discussed in the next section.

4.4. Economic Feasibility of a New Operation Model of PVAC System. Though the PVAC system contributes to clip peak and fill valley for the grid, the high LCC limits its commercialization seriously. To explore the development of the PVAC system, a new operation model is proposed. During summer and winter days, the system operates the "PVAC mode," which consumes electricity itself and sells surplus electricity to the grid. During other days, because the air conditioning system operates occasionally, the system sells its total generated electricity and purchases electricity from the grid when it requires. The LCC can be decreased and the results are shown in Table 12.

It can be concluded that case 1 has better economic benefits compared with the "PVAC model," while case 2 shows poor economic performance. Thus, we can conclude that when there is a large peak electricity requirement, it is better to operate the system in this "new model." In fact, this also helps the grid clip the peak load and fill the valley load during the peak time of summer and winter. But for cases like case 2, which has a lesser ratio of peak electricity, it is better to run the "PVAC model" both for users and the grid than decomposed PV and air conditioning and TAC system.

\section{Conclusions}

This paper presents economic feasibility comparisons between PVAC system, TAC system, and decomposed PV and air conditioning system of the three typical application cases for distributed PV air conditioning. Case 1 refers to the typical operation model of a supermarket, case 2 presents the application case of an office building, and case 3 is a typical residence in most rural areas of China. To obtain more accurate results, a TRNSYS simulation model is built to calculate the annual electricity generation, consumption, and surplus, which is sold to the grid.

According to the results of the simulation, LCC, and sensitivity analysis, the costs of equipment and peak electricity are the main costs, which are expected to decrease a lot in the near future with technological progress. When the system operates in all three cases, the PVAC system shows better economic benefits even when the peak electricity price is lower than the present value. In the three cases, the LCC of PVAC is $\$ 761.3, \$ 395.8$, and $\$ 634$ less than the LCC of TAC, for an average of $16.7 \%$ less. The PVAC of all three cases shows a better economy than the LCC of TAC, even when the parameters of equipment cost, interconnection price, and discount rate are perturbed by $20 \%$.

Considering that the on-grid price of the centralized PV electricity is higher than the distributed price, economic benefit comparison between PVAC and decomposed PV and air conditioning is carried out. The PVAC shows better economic performance for case 2 when the curtailment rate is over $9.53 \%$. For case 1, there is an always economic advantage of $\mathrm{PV}$ air conditioning regardless of curtailment rate.

However, a lesson can be learned from the decomposed $\mathrm{PV}$ and air conditioning. By operating on a new model, more benefits can be achieved for case 1 . But for case 2 consumes less peak electricity compared with case 1 , the economic advantage caused by higher on-grid price is offset by an equipment cost increase of electricity distribution.

In the future, we will have a corresponding research on the operation model about PVAC, TAC, and decomposed $\mathrm{PV}$ and AC systems. Although we have proposed a simple model about it in this paper, we will propose a detailed operation model to minimize the value of LCC.

\section{Data Availability}

The data used to support the findings of this study are included within the article.

\section{Conflicts of Interest}

The authors declare that there are no conflicts of interest regarding the publication of this paper.

\section{Acknowledgments}

This work was supported by the National Key R \& D Program of China (2018YFB0905200) and the science project of State Grid Sichuan Electric Power Corporation (SGTYHT/18-JS-199).

\section{References}

[1] X. Su, X. Bai, C. Liu, R. Zhu, and C. Wei, "Research on robust stochastic dynamic economic dispatch model considering the uncertainty of wind power," IEEE Access, vol. 7, pp. 147453-147461, 2019.

[2] C. Wei, M. Benosman, and T. Kim, "Online parameter identification for state of power prediction of lithium-ion batteries in electric vehicles using extremum seeking," International Journal of Control, Automation and Systems, vol. 17, no. 11, pp. 2906-2916, 2019.

[3] F. Cheng, L. Qu, W. Qiao, C. Wei, and L. Hao, "Fault diagnosis of wind turbine gearboxes based on DFIG stator current envelope analysis," IEEE Transactions on Sustainable Energy, vol. 10, no. 3, pp. 1044-1053, 2019.

[4] S. Afşar, L. Brotcorne, P. Marcotte, and G. Savard, "Achieving an optimal trade-off between revenue and energy peak within a smart grid environment," Renewable Energy, vol. 91, pp. 293-301, 2016.

[5] A. Al-Alili, Y. Hwang, and R. Radermacher, "A hybrid solar air conditioner: experimental investigation," International Journal of Refrigeration, vol. 39, pp. 117-124, 2014. 
[6] Z. Zapalowicz and A. Opiela, "Boundary value of the air distribution coefficient that ensures working effectivity of the air-condition system connected with ground heat exchanger and with PV installation," Sustainable Cities and Society, vol. 42, pp. 93-99, 2018.

[7] M. J. Goldsworthy, "Building thermal design for solar photovoltaic air-conditioning in Australian climates," Energy and Buildings, vol. 135, pp. 176-186, 2017.

[8] B.-J. Huang, T.-F. Hou, P.-C. Hsu et al., "Design of direct solar PV driven air conditioner," Renewable Energy, vol. 88, pp. 95-101, 2016.

[9] F. J. Aguilar, S. Aledo, and P. V. Quiles, "Experimental analysis of an air conditioner powered by photovoltaic energy and supported by the grid," Applied Thermal Engineering, vol. 123, pp. 486-497, 2017.

[10] F. Aguilar, D. Crespí-Llorens, and P. V. Quiles, "Technoeconomic analysis of an air conditioning heat pump powered by photovoltaic panels and the grid," Solar Energy, vol. 180, pp. 169-179, 2019.

[11] D. Fischer, K. B. Lindberg, H. Madani, and C. Wittwer, "Impact of PV and variable prices on optimal system sizing for heat pumps and thermal storage," Energy and Buildings, vol. 128, pp. 723-733, 2016.

[12] Z. Liu, A. Li, and Q. Wang, "Performance study of a quasi grid-connected photovoltaic DC air conditioner in the hot summer zone," Applied Thermal Engineering, vol. 121, pp. 1102-1110, 2017.

[13] P. Wei, Y. Hongwen, Z. Yongzhe, and Y. Hui, "Solar photovoltaic based air cooling system for vehicles," Renewable Energy, vol. 130, pp. 25-31, 2018.

[14] C. Wei, X. Xu, Y. Zhang, and X. Li, "A survey on optimal control and operation of integrated energy systems," Complexity, vol. 2019, Article ID 9462158, 14 pages, 2019.

[15] H. H. Chen, S. Chen, and Y. Lan, "Attaining a sustainable competitive advantage in the smart grid industry of China using suitable open innovation intermediaries," Renewable and Sustainable Energy Reviews, vol. 62, pp. 1083-1091, 2016.

[16] C. Wei, Z. Shen, D. Xiao, L. Wang, X. Bai, and H. Chen, "An optimal scheduling strategy for peer-to-peer trading in interconnected microgrids based on RO and Nash bargaining," Applied Energy, vol. 275, Article ID 117024, 2021.

[17] Building Energy Research Center of Tsinghua University, Annual Development Report of China Building Energy Efficiency, China Architecture \& Building Press, Beijing, China, [in Chinese], 2015.

[18] S. Bolocan and I. Boian, "Solar cooling for energy saving. can we afford not to use the heat of the sun?" Bulletin of the Transilvania University of Braşov, vol. 3, p. 52, 2010.

[19] R. M. Lazzarin, "Solar cooling: PV or thermal? a thermodynamic and economical analysis," International Journal of Refrigeration, vol. 39, no. 4, pp. 38-47, 2014.

[20] C. Infante Ferreira and D.-S. Kim, "Techno-economic review of solar cooling technologies based on location-specific data," International Journal of Refrigeration, vol. 39, no. 1, pp. 23-37, 2014.

[21] A. Allouhi, T. Kousksou, A. Jamil, T. El Rhafiki, Y. Mourad, and Y. Zeraouli, "Economic and environmental assessment of solar air-conditioning systems in Morocco," Renewable and Sustainable Energy Reviews, vol. 50, pp. 770-781, 2015.

[22] E. Tarigan, F. D. Kartikasari, M. Fleicher, and B. Howley, "Study of PV powered air conditioning for a classroom of university of surabaya," in Proceedings of the 2015 International Conference on Technology, Informatics, Management,
Engineering \& Environment (TIME-E), pp. 121-126, Samosir, Indonesia, September 2015.

[23] F. J. Aguilar, P. V. Quiles, and S. Aledo, "Operation and energy efficiency of a hybrid air conditioner simultaneously connected to the grid and to photovoltaic panels," Energy Procedia, vol. 48, pp. 768-777, 2014.

[24] Y. Li, G. Zhang, G. Z. Lv, A. N. Zhang, and R. Z. Wang, "Performance study of a solar photovoltaic air conditioner in the hot summer and cold winter zone," Solar Energy, vol. 117, pp. 167-179, 2015.

[25] The State Council, Regulations for the Implementation of the PRC Enterprise Income Tax Law, China Legal Publishing House, Beijing, China, 2007.

[26] Z. Yanju, H. U. Fengying, Z. Zhenglong, Z. Xiongwei, S. O. Business, and C. S. University, "Impact of optimal carbon tax rate on supply chain structure and social welfare," Systems Engineering-Theory \& Practice, vol. 37, no. 4, pp. 886-900, 2017.

[27] Y. Fu, X. Liu, and Z. Yuan, "Life-cycle assessment of multicrystalline photovoltaic (PV) systems in China," Journal of Cleaner Production, vol. 86, pp. 180-190, 2015.

[28] J. Ally and T. Pryor, "Life cycle costing of diesel, natural gas, hybrid and hydrogen fuel cell bus systems: an Australian case study," Energy Policy, vol. 94, pp. 285-294, 2016.

[29] L. Qiangqian, "Performance of lead-carbon batteries and their applications in electricity storage," Power Construction, vol. 35, no. 11, pp. 117-121, 2014, [in Chinese].

[30] State Grid Shanghai Municipal Electric Power Company, Shanghai Sales Tariff, [EB/OL]. 2016, http://www.sh.sgcc.com.cn/ html/main/col7/2016-06/21/20160621144920167955047_1.html.

[31] T. Zhanlian and J. Chen, "Lead carbon ultrabatteries for energy storage," Energy Storage Science and Technology, vol. 4, no. 6, pp. 546-555, 2015, [in Chinese].

[32] G. Lv, "Research on Independent Photovoltaic Air Conditioning System," Shanghai Jiaotong University, Shanghai, China, 2012, (in Chinese).

[33] NEA (National Energy Administration), Give Full Play to the Role of Price Leverage to Help Supply-Side Structural Reforms, National Energy Administration, Beijing, China, 2016, http:// www.nea.gov.cn/2016-05/04/c_135333301.htm.

[34] Nation Development and Reform Commission, Circular of the national development and Reform Commission on improving the on grid tariff mechanism for photovoltaic power generation, [EB/OL], 2019, https://www.ndrc.gov.cn/xxgk/ zcfb/tz/201904/t20190430_962433.html.

[35] W. Zhao, N. Zhang, C. Kang, Y. Wang, P. Li, and S. Ma, "Estimation method of conditional prediction error probability distribution of photovoltaic power generation output," Power system automation, vol. 39, no. 16, pp. 8-15, 2015. 